This item was submitted to Loughborough's Research Repository by the author.

Items in Figshare are protected by copyright, with all rights reserved, unless otherwise indicated.

\title{
Participation, barriers, and opportunities in PFI: the United Kingdom experience
}

PLEASE CITE THE PUBLISHED VERSION

PUBLISHER

(c) ASCE

VERSION

AM (Accepted Manuscript)

LICENCE

CC BY-NC-ND 4.0

\section{REPOSITORY RECORD}

Carrillo, Patricia M., Herbert S. Robinson, Peter Foale, Chimay J. Anumba, and Dino Bouchlaghem. 2019. "Participation, Barriers, and Opportunities in PFI: The United Kingdom Experience". figshare. https://hdl.handle.net/2134/4229. 
This item was submitted to Loughborough's Institutional Repository (https://dspace.lboro.ac.uk/) by the author and is made available under the following Creative Commons Licence conditions.

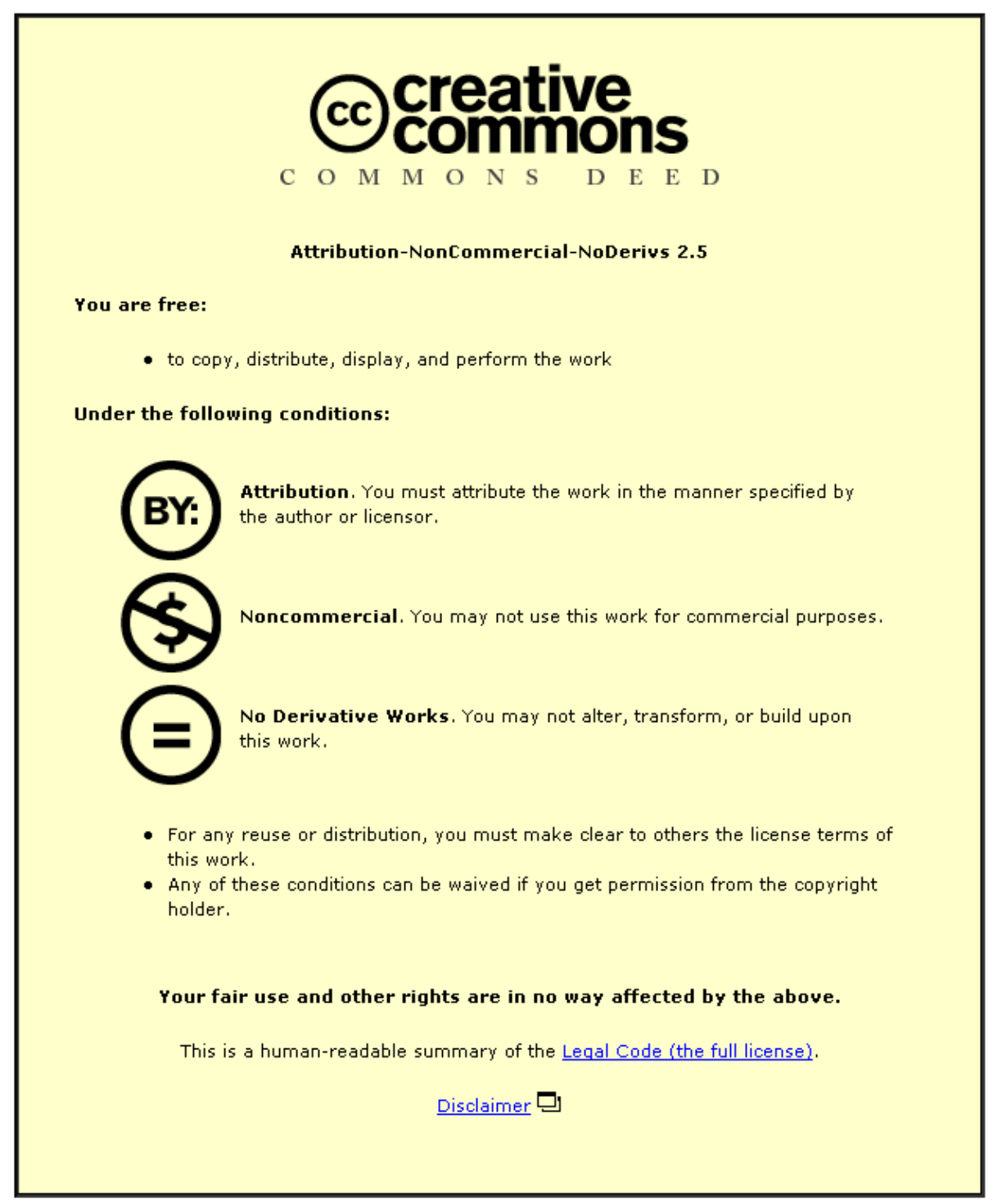

For the full text of this licence, please go to: http://creativecommons.org/licenses/by-nc-nd/2.5/ 


\title{
Participation, Barriers and Opportunities in PFI: The UK Experience
}

\author{
Patricia Carrillo ${ }^{1}$, Herbert Robinson ${ }^{2}$, Peter Foale ${ }^{3}$, Chimay Anumba ${ }^{4}$ and Dino \\ Bouchlaghem $^{5}$
}

\begin{abstract}
Private Finance Initiative $(\mathrm{PFI})$ projects play an increasingly important role for both the UK government and the construction sector. It is still a relatively new form of procurement that requires a wide range of specialist advice during the bidding stage and in-depth knowledge of how the facility will perform in the long term. This paper investigates the level of participation in PFI projects in the UK, the opportunities available for the construction sector, the types of problems experienced and the challenges for the future. It achieves this by analyzing the results of a questionnaire survey of a large number of client and construction organizations. The study finds that there is a wide gap in the level of PFI experience between client and construction organizations, affordability of PFI projects and high bidding costs are key issues for client and construction organizations respectively and, given the nature of PFI projects, there is considerable scope for knowledge transfer both during the project and between different PFI projects.
\end{abstract}

CE Database subject headings: construction companies, contracts, procurement, partnerships, privatization

${ }^{1}$ Professor, Department of Civil and Building Engineering, Loughborough University, Loughborough University, Leicestershire, LE11 3TU, England (Email:

P.M.Carrillo@lboro.ac.uk, Tel.: +44 1509 222634) 
${ }^{2}$ Senior Lecturer, Department of Engineering, Science and the Built Environment, London South Bank University, 103 Borough Road, London SE1 OAA, England (Email: robinshb@Isbu.ac.uk, Tel: +44 207815 7103)

${ }^{3}$ Consultant, Initiative Consulting, 120 Cotgrave Lane, Tollerton, Nottinghamshire, NG12 4FY, England (Email: peter@initiative-consulting.com, Tel.: +44 1159 376531)

${ }^{4}$ Professor, Department of Civil and Building Engineering, Loughborough University, Loughborough University, Leicestershire, LE11 3TU, England (Email:

C.J.Anumba@lboro.ac.uk, Tel.: +44 1509 222615)

${ }^{5}$ Professor, Department of Civil and Building Engineering, Loughborough University, Loughborough University, Leicestershire, LE11 3TU, England (Email:

N.M.Bouchlaghem@lboro.ac.uk. , Tel.: +44 1509 223775) 


\section{Introduction}

The Private Finance Initiative (PFI) was launched in the UK in 1992. Since then it has become an increasingly popular mechanism for procuring public infrastructure in various countries. PFI is one of three categories of Public Private Partnerships (PPP). The aim of PFI is to bring the private sector's finance, management skills and expertise into the provision of public sector facilities and services (Akintoye et al., 1998). The other forms of PPP focus on private sector ownership of state-owned businesses and the selling of government services to other markets. In all cases, an underlying principle of PPP schemes is that certain construction and operational risks associated with the provision of public services should be transferred away from the public sector to where they can be best and most appropriately managed.

The UK has approved a total of 700 PFI projects to date and over the next five years approximately 200 projects worth $\$ 400 \mathrm{~B}(£ 200 \mathrm{~B})$ are planned. With such a track record, several articles document the history of PFI in the UK (Grout, 1997; Ball et al., 2000; Akintoye et al., 1998). Likewise, a number of reports have been written examining the impact of PFI in the UK. These include over 50 reports by the UK's National Audit Office (NAO) , 25 reports by the Public Accounts Committee (PAC), numerous (Her Majesty) HM Treasury reports, the Audit Commission and academic papers focusing on public policy and the involvement of the construction sector. PFI plays an important role in the delivery of public services and hence the involvement of public bodies in examining PFI policy and processes. For example, the NAO is the primary body charged with assessing the government's PFI program, the PAC follows up on the reports produced by the NAO and the Audit Commission audits public money spent by local authorities (HM Treasury, 2003). 
PFI has spread on a global basis with the attraction of governments being able to provide public infrastructure using a "mega-credit card" (Hodge and Greve, 2007). Hodge and Greve (2007) also provide a very useful international perspective of the various approaches to PPPs using examples from the US, Australia and Europe. They emphasize the diversity of approaches adopted by various governments and the range of experiences in terms of success and failures. Zhang (2005) also reports on the results of PPP/PFI projects from 13 countries. He categorizes a wide range of barriers into six aspects. These include (1) social, political and legal risk; (2) unfavorable economic and social conditions; (3) inefficient public procurement frameworks; (4) lack of mature financial engineering techniques; (5) problems related to the public sector and; (6) problems related to the private sector. Kumaraswamy and Morris (2002) also investigate lessons learned on PFI mega projects in Asia and propose a "BOT body of knowledge".

PFI projects are much more complex than traditional forms of procurement and therefore require a much longer lead-in time before construction commences. They also require a change in culture with construction companies having an early involvement as well as a continuing role during the operation of the facility. Typically, PFI projects consist of 13 main stages from Needs Assessment to Hand back. These stages require a mix of different companies involving financial advisors and funding suppliers, specialist legal advisors for the complex contractual issues, construction experts in the form of designers, construction contractors, cost planners, facilities managers, etc.

\section{Why PFI?}

A number of authors claim that PFI was introduced for political reasons, namely to provide public sector facilities to minimize the Public Sector Net Cash Requirement 
(Kerr, 1998; Construction Industry Council, 1998, Clarke and Root, 1999; Ruane, 2000; Ball et al., 2000). However, the current UK government still sees PFI as a relatively small part of total public investment, currently between 10 and $15 \%$ and necessary where there are major and complex projects with significant ongoing maintenance and soft service requirements (HM Treasury, 2003 and 2006). It believes that the private sector has a role to play in offering project management skills, more innovative design, the ongoing provision of facility management (FM) services and risk management expertise. This is further supported by recent articles that document the significant cost overruns on some central and local government projects (New Civil Engineer, 2005). In support of $\mathrm{PFI}$, the article claimed that the increasing use of PFI will reduce the risk exposure of local government by transferring it to contractors.

\section{Flaws In PFI}

Much of the criticism of PFI focuses on the Value for Money (VFM) achieved by projects (Gaffney and Pollock, 1999; Price et al., 1999; Ball et al., 2000; Akintoye et al., 2003; Bing et al., 2004), the government bias towards PFI (Ruane, 2000; Edwards and Shaoul, 2003), the time and expense required to procure and deliver schemes (Birnie, 1999) and the management and transfer of risk by the private and public sectors (Akintoye et al, 1998; Froud, 2003, Bing et al., 2005). For example, the Institute for Public Policy Research (IPPR, 2001) concluded that "PFI projects do demonstrate value for money in some sectors but not universally". They also identified specific problems in the health and education sectors. The bias towards PFI is interpreted in terms of "The trouble with PFI is you had no choice. You either had a capital development with PFI or you had nothing at all" (National Health Service (NHS) Trust quotation in Ruane, 2000). 
In recent years the UK Government has attempted to counteract these criticisms by conducting research (HM Treasury, 2003; HM Treasury, 2006 and Partnerships UK, 2006). The HM Treasury (2003) reports on a survey conducted in 2002 on 70 projects. The projects surveyed project managers on projects in the Transport, Justice/Custodial, Health, Schools and Defense sectors. The results indicated that:

- $89 \%$ of projects were delivered on time or early;

- all PFI projects (in a sample of 61 projects with small capital value, and IT projects) were delivered within public sector budgets; and

- $\quad 77 \%$ of public sector managers agreed that their projects met their initial expectations.

The HM Treasury has also conducted research to investigate whether PFI had delivered the benefits expected from its completed procurements. The research looked at:

- Construction performance: The sample showed that $88 \%$ of projects were delivered on time or early;

- Delivery against budgets: The findings showed that all budget increases were due to changes in public sector requirements;

- Bidder selection: Deals were considered competitive and averaged four bidders each with $70 \%$ of bidders selected on the basis of price, design and reputation;

- Procurement times: This was particularly problematic with lengthy delays between invitation to bid and financial close. Some early healthcare projects (1994-1998) took an average of 40 months with an upper limit of 60 months; and

- Operational performance: Over three quarters of public sector clients were satisfied with performance and $24 \%$ were dissatisfied. 
The HM Treasury (2006) report describes the results of a 2005 survey conducted by Partnerships UK (2006). They surveyed 400 operational projects and received 105 responses. A further 12 projects were selected for detailed reviews using semistructured interviews. The report concluded that:

- $79 \%$ of projects reported that services standards were delivered always or almost always;

- $96 \%$ of projects were at least "satisfactory";

- $89 \%$ of projects had services provided in line with the contract or better;

- $83 \%$ of projects reported that their contracts always or almost always accurately specify the services required; and

- $72 \%$ of projects report good or very good performance.

\section{PFI Improvements}

The Bates Review (Bates, 1997) endorsed the use of PFI as a procurement approach but a number of recommendations were made for improvements in the contracting process. These recommendations were accepted in full by central government. Based on more recent research on PFI performance, the government introduced a further set of initiatives aimed at improving the operation of PFI. These include:

- Improving public sector procurement skills. For example, the Department of Health, HM Prison Service and the Highways Authority now have specialized private finance units;

- Bodies such as Partnerships UK and the Public Private Partnerships Programme (4Ps) have been set up to provide advice, support and training to the public sector to strengthen its client function; 
- Gateway Reviews have been introduced by the Office of Government Commerce to allow an independent review of the organizational readiness of public bodies to move their projects forward at pre-defined critical stages in the procurement process;

- The Commission for Architecture and the Built Environment (CABE) is helping to advance the concept of high quality design on public procurement;

- Standard Contracts and other supporting documentation have been introduced to reduce the length and cost of negotiation periods, ensure consistency in the approach to risk transfer and management and achieve consistency in the approach to the structure of PFI contracts; and

- New schemes targeting special markets have been introduced. These include (a) the NHS LIFT (Local Improvement Finance Trust) to provide community-based health facilities, and (b) Building Schools for the Future (BSF), a program for rebuilding and renewing all secondary schools.

In addition, there has been a significant maturing within the PFI market as both private and public sector bodies become more used to the whole process and the experience of completing projects is spread widely. This applies particularly to the construction phase of projects but is also starting to become more widespread in the operational phase. It is envisaged that these improvements will help to address the majority of criticisms leveled at PFI although some philosophical objections to PFI continue to be made.

\section{Research Methodology}

A questionnaire survey was adopted as the most appropriate manner in which to gain the views of a large number of client and construction organizations. The aim of the survey was to: 
- identify the level of participation in PFI;

- review current practices in procurement, construction and operation of PFI;

- investigate barriers and enablers; and

- identify opportunities and the potential scope for improvement.

The questionnaire was informed by a review of the academic and industry literature, and discussions with UK construction companies involved in PFI projects.

Two separate questionnaire surveys were conducted in 2004. One was specific to client organizations and the second was specific to construction organizations. Copies of these are available upon request. A total of 87 questionnaires were sent to client organizations using a database of NHS, education-sector, and transport PFI projects. The respondents included PFI project/program directors and managers, strategic directors, planning and development directors and other senior managers and directors. A total of 121 large construction organizations were contacted by telephone using the latest database from the 2003 New Civil Engineer's Consultants' File (2003a) and 2003 Contractors' File (2003b). Questionnaires were then sent to 86 construction organizations involved in PFI. The respondents included partners, associates, PFI/PPP directors, procurement, contract and commercial managers, business development directors, bid directors and managers and other senior personnel involved in PFI projects.

A total of 100 completed questionnaires were received out of 173 giving an overall response rate of $58 \%$. The data collected was analyzed from the perspectives of the different stakeholders (client and construction organizations) to establish current practices and perceptions, identify key sources of problems, the scope for improvement, knowledge transfer issues and future challenges. 
$48 \%$ of the respondents were client organizations and $52 \%$ were construction organizations. The client organizations included 27 borough and county councils involved in the education and transport sectors and 21 NHS Trusts involved in the health sector. $97 \%$ of the client organizations were large NHS Trusts and Local Authorities employing more than 1500 people. The construction organizations included 25 contracting and 27 consulting (design) organizations. Of these respondents, 35\% of the construction organizations employ less than 500 people, another $35 \%$ employ between 500 and 1,500 and the remaining 30\% employ more than 1,500 people.

\section{Findings and Discussion}

The main findings of the survey are discussed below. The responses are divided into the following categories:

- Perception and Participation;

- Enablers and Barriers to PFI; and

- Knowledge Transfer Mechanisms.

\section{Perception and Participation}

Companies' views on specific aspects of PFI projects were investigated to understand their level of participation in PFI work.

\section{Costs}

The value for money obtained on PFI has often been questioned in relation to the cost of traditional forms of procurement. The survey found that both client and construction 
organizations considered the PFI bidding costs and the design and construction costs to be higher than that for traditional procurement for all project sizes (Table 1).

<Insert Table 1 here>

The figures show that the majority of client and construction organizations believe that the bidding costs of PFI are higher, regardless of project size, whereas only a third believe these costs are higher for the design and construction phases. The main reason for this is the cost of the specialist expertise required during the bidding stage and the lengthy negotiation periods for PFI projects.

Innovation, Risk and Value for Money

PFI projects were expected to bring about increased innovation (due to the consortia created), transfer risk to the private sector, and provide value for money for the government. de Lemos et al. (2003) found that whilst designers are free to innovate in their designs, contractors were conservative in the materials they used. Also certain sectors, such as health, left little room for innovation because of the standards required. The results showed the following

- $54 \%$ of respondents considered PFI to produce improved innovation in design;

- $\quad 52 \%$ considered risks and rewards were appropriately managed; and

- $52 \%$ considered PFI provided value for money for the whole life performance. These figures show that neither client nor construction organizations are completely convinced that PFI projects deliver the anticipated benefits. It is interesting to note that the construction organizations' higher ratings for those areas under their control e.g. promoting innovation in design and value for money whilst they downgrade the area that is not under their control i.e. risk. 


\section{Motivation for PFI}

Client and construction organizations have different reasons for participating in PFI projects. Client organizations identified the following as key drivers:

- government policy; and

- no initial capital funding requirement.

Construction organizations, on the other hand, are motivated mainly by:

- the steady and long-term income stream;

- $\quad$ higher returns and profitability; and

- diversified workload.

Figure 1 shows most important motivation factors selected by the 48 client and 52 construction organizations.

<Insert Figure 1 here $>$

\section{PFI Activity Levels}

The survey showed that most activity is, and is expected to remain, in the health, education and transport sectors although there are indications of opportunities in other non-traditional sectors such as social housing and water. Health at $27 \%$ PFI market share is expected to remain the dominant sector in terms of share of PFI projects followed by Education (23.6\%) Transport (23.1\%), Defense (8.5\%) and Custodial (3.4\%). Also, $62 \%$ of client organizations and $79 \%$ of construction organizations expected their PFI activity to increase in the short term (next two years). Whilst the UK remains the dominant market for the respondents, the EU, Canada, South Africa, Australia, the Far East and Middle East are considered emerging markets for PFI/PPP market. 


\section{Enablers and Barriers to PFI}

$\mathrm{HM}$ Treasury acknowledges that there is room for improvement on PFI projects ( $\mathrm{HM}$ Treasury, 2003). In this regard, the following issues are considered important:

- PFI Expertise;

- $\quad$ Barriers to PFI;

- Procurement periods; and

- Unique PFI issues.

\section{PFI Expertise}

$\mathrm{PFI}$, as a relatively new form of procurement, has a low level of expertise available. This is much more prevalent in client organizations because of their one-off PFI projects. A National Audit Office report (NAO, 2001) pointed out the need for local authorities to have the right skills to manage PFI projects and the problems with staff continuity on PFI projects. The survey results showed an average experience of construction organizations in PFI is 7.3 years compared to 5.4 years for client organizations.

Construction organizations have more experienced staff compared to client organizations. Overall, about $73 \%$ of construction organizations rated their company's expertise in PFI to be "good" or "very good", compared with 64\% of client organizations. Just under a quarter of organizations rated their expertise as "satisfactory". No organization rated their expertise as "very poor" "poor".

\section{Barriers to PFI}

A number of barriers affect the participation of organizations in PFI projects. Figure 2 shows the most important barriers. 
$<$ Insert Figure 2 here>

The most significant barriers identified by client organizations, in order of importance, are:

- $\quad$ high transaction and bidding cost;

- complex contracts; and

- lengthy negotiation periods.

For construction organizations the most significant barriers identified are:

- the high transaction and bidding costs associated with PFI;

- track record;

- lengthy negotiation periods; and

- inexperienced staff

\section{Procurement Periods}

The time taken for PFI projects to be finalized is a growing concern as it has a significant influence on bidding and transaction costs. Little seems to have changed since Ezulike et al (1999) highlighted the problem of the extensive time required for bidding. Table 2 shows the average time scale in months from Preliminary Invitation To Negotiate - PITN (stage 6 of 13) to Preferred Bidder (stage 9) and Financial Close (stage 10 of 13). $<$ Insert Table 2 here $>$

Table 2 shows that Defense PFI procurement remains a major problem characterized by an average time of 34.5 months, well above the other sectors. Both client and construction organizations agree that the procurement time is too long. $63 \%$ of client organizations and $80 \%$ of construction organizations believe that the time lapse between PITN (Stage 6) and Preferred Bidder (Stage 9) is too long. Similarly, 65\% of client organizations and $75 \%$ of construction organizations believe that the Preferred Bidder 
(Stage 9) to Financial Close (Stage 10) period is too long. The result of these long periods is that both construction and client organizations have staff involved in PFI projects for lengthy periods, thus tying up resources without a known outcome.

\section{Unique PFI Issues}

There are a number of unique issues associated with PFI at the procurement, development and delivery stages that are of growing concern to client and construction organizations. Table 3 shows respondents' perception of issues for three stages of the PFI process. The issues of main concern are those rated as very significant (4) or highly significant (5).

$<$ Insert Table 3 here $>$

In general, client organizations tend to experience far more problems with PFI projects than construction organizations. In the Procurement stages, affordability/funding gap is very highly rated by client organizations with almost all of the respondents (92\%) agreeing that these are very significant and structural issues at the heart of PFI projects. Also, lack of staff resources is more of a problem for client organizations (54\%) than for construction organizations (29\%). Strongly linked with the affordability issues are the problems of design change orders/variations (56\%) and establishing life cycle costs (44\%). As PFI is essentially a service provision on behalf of client organizations, there is concern about sustaining the service level during the operation of completed facilities. This is reflected in a rating of $48 \%$ for client organizations compared to $17 \%$ for construction organizations.

The most significant issues from the perspective of construction organizations during the procurement stage are affordability/funding gap (70\%), inadequate client brief/requirements (60\%) and poor project management (42\%). At the development 
stage there are concerns about design change orders/variations (43\%). However, no highly significant issues were identified during the Delivery Stage. These results were reflected in the average scores where affordability/finding gap was highlighted and relatively low scores (i.e. insignificant) for the development and Delivery stages.

\section{Knowledge Transfer Mechanisms}

An Ernst and Young report (2002) report argued that "it is perhaps a good time to reflect on how PFI has developed and why it has turned out to be more challenging than the original enthusiasts thought". The report indicated that there are still concerns over the level of knowledge sharing. The Audit Commission (2003) highlighted the need for the early lessons learned in PFI to be "recycled effectively during future investment" to improve performance. HM Treasury (2004) also stressed the importance of information sharing for the better performance of PFI projects. The following section investigates the structures in place to facilitate knowledge transfer on PFI projects in terms of:

- Scope for learning on PFI projects;

- Organizational readiness for knowledge transfer; and

- Knowledge transfer tools used.

\section{Scope for learning on PFI projects}

Zhang and Kumaraswamy (2001) stressed the importance of learning on PFI projects and the need for a 'PFI/PPP body of knowledge'. The scope for learning from PFI consortium members and the capture of project knowledge are important to encourage continuous improvement. $76 \%$ of client and construction organizations believe that there is much scope for improvement by learning from consortium members. Likewise, $70 \%$ of client organizations and $76 \%$ of construction organization believe there is much scope to improve the capture of knowledge on PFI projects. 
Respondents were asked to identify important issues requiring greater sharing between projects. A wide range of issues were highlighted; these can be classified as follows:

- Commercial knowledge (e.g. payment mechanisms, financial modeling, facilities management cost benchmarking, forecasting data, whole life cycle costing, and value management);

- Legal/contract documents (e.g. legal obligations, risk allocation and risk management);

- Sector knowledge (e.g. health care provision, medical innovation, space requirements);

- Guidance Notes (e.g. those from Office of Government Commerce and HM Treasury);

- Technical knowledge (e.g. design requirements, construction details, buildability, scope of works);

- Best practice and project reviews to learn from previous projects;

- Client interface and management of expectations; and

- Staff expertise, availability and mobility.

At the moment, PFI experience is transferred in two main ways: through face-to-face contact or via documents. By far the most common mechanism for transferring PFI experience was using face-to-face approaches. In order of rank these approaches were as follows:

- Meetings, workshops, forums, etc. to disseminate PFI knowledge;

- Core and highly experienced PFI teams;

- Key Individuals e.g. PFI Director, Operations Director as focal points; 
- Staff rotation/redeployment;

- Project reviews and project close out meetings;

- Communities of Practice to address key issues; and

- Mentoring.

Using documents to transfer experience was less common. The main mechanisms used were best practice documents and feedback reports. This may be because, as yet, there are an insufficient number of completed projects to produce best practice documents.

Organizational readiness for knowledge transfer In order to transfer knowledge across PFI projects and across PFI sectors, organizations must have a culture that encourages and supports it. Thus an organization's readiness for knowledge transfer can be assessed. Respondents were asked to rank five criteria from 1 (strongly disagree) to 5 (strongly agree). Table 4 shows the average scores and highlights the main problem areas.

$<$ Insert Table 4 here $>$

The table shows that there is an innate recognition that knowledge sharing should take place and employees are willing to share. The table also highlights the reluctance to adopt performance measurement to monitor progress and the introduction of rewards schemes to encourage knowledge sharing. The latter concurs with previous findings by Sheehan (2000) and Carrillo (2004) which highlighted the reluctance of construction organizations to use rewards to foster knowledge sharing, because of the adverse effect on teamwork. 
Knowledge Transfer Tools

A number of different tools are used for capturing lessons learned on PFI projects (Figure 3) . The most significant tools identified by construction organizations are discussion forum, followed by post project reviews, and best practice documents. For client organizations, the most significant tools are post-project reviews, followed by discussion forum, best practice documents, seminars and conferences. The most significant IT tools are the intranet/extranet followed by a low adoption of content and document management systems and Groupware.

<Insert Figure 3 here $>$

\section{The Way Forward}

Both past and present UK governments have recommended PFI projects as the way forward for the redevelopment of the public infrastructure. The current government is committed to making PFI succeed and has responded to criticism with a series of measures aimed at streamlining and introducing greater certainty into the PFI process for both public and private participants. However, there are a number of issues that still need to be addressed:

- High bidding cost;

- Lengthy procurement periods;

- Lack of expertise in the public sector both in terms of numbers and amount of experience;

- Convincing the public as well as private and public sector that PFI delivers in terms of innovation and value for money; and

- Exploiting lessons learned from previous projects. 
PFI bidding costs and the lengthy bidding periods are a major concern. It is unsustainable for a private company to have staff involved on a project for a five year period without a positive outcome. Hence the reasons for the excessive delays need to be further investigated to understand why certain types of projects are so problematic. This problem would hopefully be alleviated as both public and private participants, as well as their technical advisors, gain more experience on PFI. Herein, lies the need for learning and management of PFI knowledge stressed by many different organizations.

The lack of expertise negatively impacts on the success of PFI. Local authorities, with their limited PFI expertise, are struggling to keep up with the private sector. The creation of Public Private Partnerships Programme (4Ps) has helped to address this but it does not detract from the fact that there is a need for developing PFI expertise in the public sector more proactively if this is to continue to be the way forward in procuring a range of public infrastructure projects.

The government is attempting to show, through research, the positive outcomes of completed PFI projects. However, there is a bias in that the studies conducted so far have been on behalf of the government and use a limited amount of projects with a very narrow focus (mainly small projects and IT projects). There is a need for more independent studies covering a range of PFI sectors and feedback from a range of clients in order for there to be an unbiased analysis of PFI performance. These will also need to continue over the medium to longer term as experience of the operational phase of individual projects grows. The true test of the merits of PFI will be the sustainability of the quality of public assets during the lifetime of the PFI contracts under which they have been provided. 


\section{Conclusions}

This paper has investigated the level of participation in PFI projects in the UK, the opportunities available for the construction sector, the types of problems experienced and the challenges for the future. This was done by conducting and analyzing the results of a questionnaire survey of 100 client and construction organizations. Many criticisms have been leveled at the government's PFI procurement policy. Research over the years has shown serious flaws in the process. The government has responded by introducing new measures to improve PFI procurement such as legislation to aid transparency, provision of standard contracts, the creation of support groups, etc. However, despite these measures problems still exist in a number of areas. This study found that the main problems stemmed from the lengthy bidding period which led to high bidding costs, the continuing lack of sufficient PFI expertise within the public sector, lack of knowledge transfer between projects and a public that is not yet convinced about the value for money provided by the private sector. The paper proposes a number of mechanisms for improving PFI procurement. These concentrate on the need for independent analysis of PFI performance, increase in the level of PFI expertise in the public sector through more structured mechanisms for proactive knowledge transfer and reduced procurement times. 


\section{References}

Akintoye, A., Hardcastle, C. Beck, M. Chinyo, E. and Asenova, D. (2003). "Achieving best value in private finance initiative procurement." Construction Management and Economics, 21(5), 461-470.

Akintoye, A., Taylor, C. and Fitzgerald, E. (1998). "Risk analysis and management of Private Finance Initiative projects." Engineering, Construction and Architectural Management, 5(1), 9-21.

Audit Commission (2003). "PFI in Schools: The Quality and Cost of Buildings and Services Provided by Early Private Finance Initiative Schemes," Audit Commission, London Ball, R., Heafey, M. and King, D. (2000). "Private Finance Initiative - a good deal for the public purse or a drain on future generations?" Policy and Politics, 29(1), 95-108.

Bates, M. (1997) Review of PFI (Public/ Private Partnerships), Her Majesty (HM) Treasury, London.

Bing, L., Akintoye, A. and Hardcastle, C. (2004). "Perceptions of value for money in the development of PFI/PPP." Journal of Financial Management of Property and Construction, 9(1), 43-52.

Bing, L., Akintoye, A. Edwards, P.J. and Hardcastle, C. (2005). "The allocation of risk in PFI/PPP construction projects in the UK." International Journal of Project Management. 23(1), 25-35.

Birnie, J. (1999). "Private Finance Initiative (PFI): UK Construction Industry Response," J. Construction Procurement, 5(1), 5-14.

Carrillo, P.M. (2004). "Managing Knowledge: a North American perspective", Proceedings of the Institution of Civil Engineers , 157(4), pp. 187-192.

Clarke, G.L. and Root, A. (1999). "Infrastructure shortfall in the United Kingdom the private finance initiative and government policy." Political Geography, 18(3), 341365. 
Construction Industry Council (1998). Constructors' Key Guide to PFI, Thomas Telford, London.

De Lemos, T., Almeida, L, Betts, M. and Eaton, D. (2003) "An examination on the sustainable competitive advantage of private finance initiative projects." Construction Innovation, 3(4), 249-259.

Edwards, P. and Shaoul, J. (2003). "Controlling the PFI process in schools: a case study of the Pimlico project." Policy and Politics, 31(3), 371-385.

Ernst and Young (2002). "Progress and Prospects: A survey of Healthcare PFI." $<\underline{\text { http://www.ey.com }>~(F e b ~ 5, ~ 2003) . ~}$

Ezulike, E.L., Perry, J.G., Hawwash, K. (1997). "The barriers to entry into the PFI market." Engineering Construction and Architectural Management, 4(3), 179-193.

Froud, J. (2003) “The Private Finance Initiative: risk, uncertainty and the state." Accounting, Organizations and Society, 28(6), 567-589.

Gaffney,D. and Pollock, A.M. (1999). "Pump Priming the PFI: why are privately financed hospital schemes being subsidized?" Public Money and Management, 17(3), 1116.

Grout, P.A. (1997) "The Economics of the Private Finance Initiative." Oxford Review of Economic Policy, 13(4), 53-66.

HM Treasury (2003). PFI: Meeting the Investment Challenge, HM Treasury, London HM Treasury (2004). Value for Money assessment Guidance, HM Treasury, London. HM Treasury (2006). PFI: Strengthening long-term partnerships, HM Treasury, London. Hodge, , G. and Greve, C. (2007). "Public-Private Partnerships: An International Review." Public Administration Review, 67(3), 545-559.

Institute for Public Policy Research (IPPR) (2001). Building Better Partnerships, IPPR, London. 
Kerr, D. (1998). "The Private Finance Initiative and the Changing Governance of the Built Environment." Urban Studies, 35(12), 2277-2301.

Kumaraswamy M.K. and Morris, D.A. (2002). "Build-Operate-Transfer-Type Procurement in Asian Megaprojects." Journal of Construction Engineering and Management, 128(2), 93-102.

National Audit Office (2001). Managing the relationship to secure a successful partnership in PFI projects. The Stationery Office, London.

National Audit Office (2007). Improving the PFI tendering Process. The Stationery Office, London.

New Civil Engineer (NCE) (2003a). 2003 Consultants File, Emap Construct Ltd, London. New Civil Engineer (NCE) (2003b). 2003 Contractors File, Emap Construct Ltd, London. New Civil Engineer (NCE) (2005). "Council Cash Cows." New Civil Engineer, 3 March, $19-21$

Partnerships UK (2006). Report on Operational PFI Projects, Partnerships UK, London.

Price, D. Gaffney, D. and Pollock, A. (1999). The only game in town: A report on the Cumberland Infirmary Carlisle PFI. Unison, London.

Ruane, S. (2000). "Acquiescence and opposition: the private finance initiative in the national Health Service." Policy and Politics, 28(3), 411-424.

Sheehan, T. (2000). "Building on Knowledge Practices at Arup." Knowledge Management Review, 3(5), 12- 15.

Zhang, X.. (2005). "Paving the way for Public-Private Partnerships in Infrastructure Development." Journal of Construction Engineering and Management, 131(1), 7180.

Zhang, X.Q., Kumaraswamy, M. (2001). "Procurement Protocols and Public-Private Partnered Projects." Journal of Construction Engineering and Management, 127(5), 351-358. 
Table 1: Organizations Considering Costs High Compared to Traditional Procurement

\begin{tabular}{|c|c|c|c|}
\hline & $\begin{array}{c}\text { Number of } \\
\text { Client } \\
\text { Organizations } \\
\text { (out of } 48 \text { ) }\end{array}$ & $\begin{array}{l}\text { Number of } \\
\text { Construction } \\
\text { Organizations } \\
\text { (out of } 52 \text { ) }\end{array}$ & $\begin{array}{c}\text { \% Total } \\
\text { Respondents }\end{array}$ \\
\hline \multicolumn{4}{|l|}{ Bidding Costs } \\
\hline Small projects $(<£ 30 M)$ & 42 & 46 & 88 \\
\hline $\begin{array}{l}\text { Medium projects (£30M - } \\
£ 70 \mathrm{M})\end{array}$ & 33 & 40 & 71 \\
\hline Large projects $(>£ 70 M)$ & 26 & 37 & 63 \\
\hline \multicolumn{4}{|c|}{ Design \& Construction Costs } \\
\hline Small projects $(<£ 30 \mathrm{M})$ & 16 & 23 & 39 \\
\hline $\begin{array}{l}\text { Medium projects (£30M - } \\
£ 70 \mathrm{M})\end{array}$ & 14 & 20 & 34 \\
\hline Large projects $(>£ 70 M)$ & 11 & 19 & 30 \\
\hline
\end{tabular}


Table 2: Procurement Periods by Private Finance Initiative sectors (in months)

\begin{tabular}{|c|c|c|c|c|c|}
\hline & Health & Education & Transport & Custodial & Defense \\
\hline \multicolumn{6}{|l|}{ Client organizations } \\
\hline Stage 6 to Stage 9 (a) & 13.0 & 13.2 & * & * & * \\
\hline Stage 9 to Stage $10(b)$ & 13.7 & 6.3 & * & * & * \\
\hline Stage 6 to Stage $10(a+b)$ & 26.7 & 19.6 & * & * & * \\
\hline \multicolumn{6}{|l|}{ Construction organizations } \\
\hline Stage 6 to Stage 9 (a) & 12.0 & 10.2 & 12.7 & 16.7 & 16.5 \\
\hline Stage 9 to Stage $10(b)$ & 11.2 & 9.3 & 8.2 & 11.2 & 18.0 \\
\hline Stage 6 to Stage $10(a+b)$ & 23.2 & 19.5 & 20.9 & 27.9 & 34.5 \\
\hline
\end{tabular}

* insufficient/no response

Stage 6: Preliminary Invitation to Negotiate

Stage 9: Preferred Bidder

Stage 10: Financial Close 
Table 3: Unique Private Finance Initiative Issues at key stages

\begin{tabular}{|c|c|c|}
\hline & $\begin{array}{c}\text { Average Score } \\
\text { - Client } \\
\text { Organizations }\end{array}$ & $\begin{array}{c}\text { Average Score - } \\
\text { Construction } \\
\text { Organizations }\end{array}$ \\
\hline \multicolumn{3}{|l|}{ Procurement Stage } \\
\hline Inadequate client brief/ requirements & 2.7 & 3.6 \\
\hline Lack of time given to bidders & 2.0 & 2.9 \\
\hline Lack of staff resources & 3.5 & 2.7 \\
\hline Difficulties establishing life cycle & 3.1 & 2.3 \\
\hline \multicolumn{3}{|l|}{ costs } \\
\hline Affordability/funding gap & 4.5 & 3.8 \\
\hline Poor project management & 2.4 & 3.2 \\
\hline \multicolumn{3}{|l|}{ Development Stage } \\
\hline Design change orders/variations & 3.5 & 3.3 \\
\hline Defects and rework & 3.1 & 2.4 \\
\hline Cost overrun & 2.3 & 2.6 \\
\hline Construction delay & 2.8 & 2.6 \\
\hline \multicolumn{3}{|l|}{ Delivery Stage } \\
\hline Difficulties in sustaining service level & 3.1 & 2.4 \\
\hline Difficulties in maintaining facilities & 2.5 & 2.3 \\
\hline Remuneration and payment dispute & 2.5 & 2.3 \\
\hline
\end{tabular}


Table 4: Organizational Readiness for Sharing Private Finance Initiative Knowledge

\begin{tabular}{lcc}
\hline & $\begin{array}{c}\text { Client } \\
\text { Organizations }\end{array}$ & $\begin{array}{c}\text { Construction } \\
\text { Organizations }\end{array}$ \\
\hline The organization recognizes that the need for managing & 3.6 & 4.0 \\
knowledge across Private Finance Initiative projects is & & 3.8 \\
strong & & 3.3 \\
People are willing to share knowledge & 3.1 & 2.1 \\
Trust and cultural barriers to knowledge sharing have & & 1.9 \\
been addressed & & 1.9 \\
The organization uses a performance measurement tool & & \\
to monitor improvement from knowledge sharing & & \\
There is a reward scheme for people contributing to & & \\
knowledge sharing &
\end{tabular}




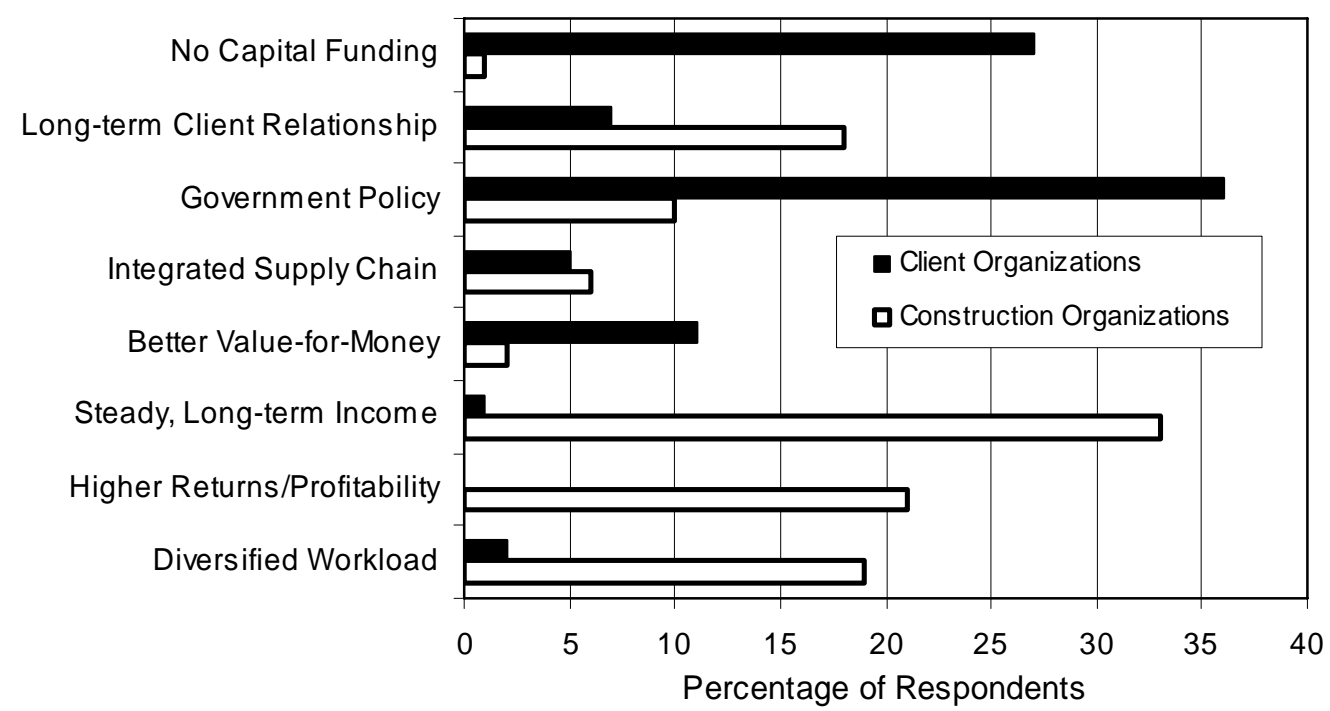

Figure 1: Motivation for Involvement in Private Finance Initiative Projects 


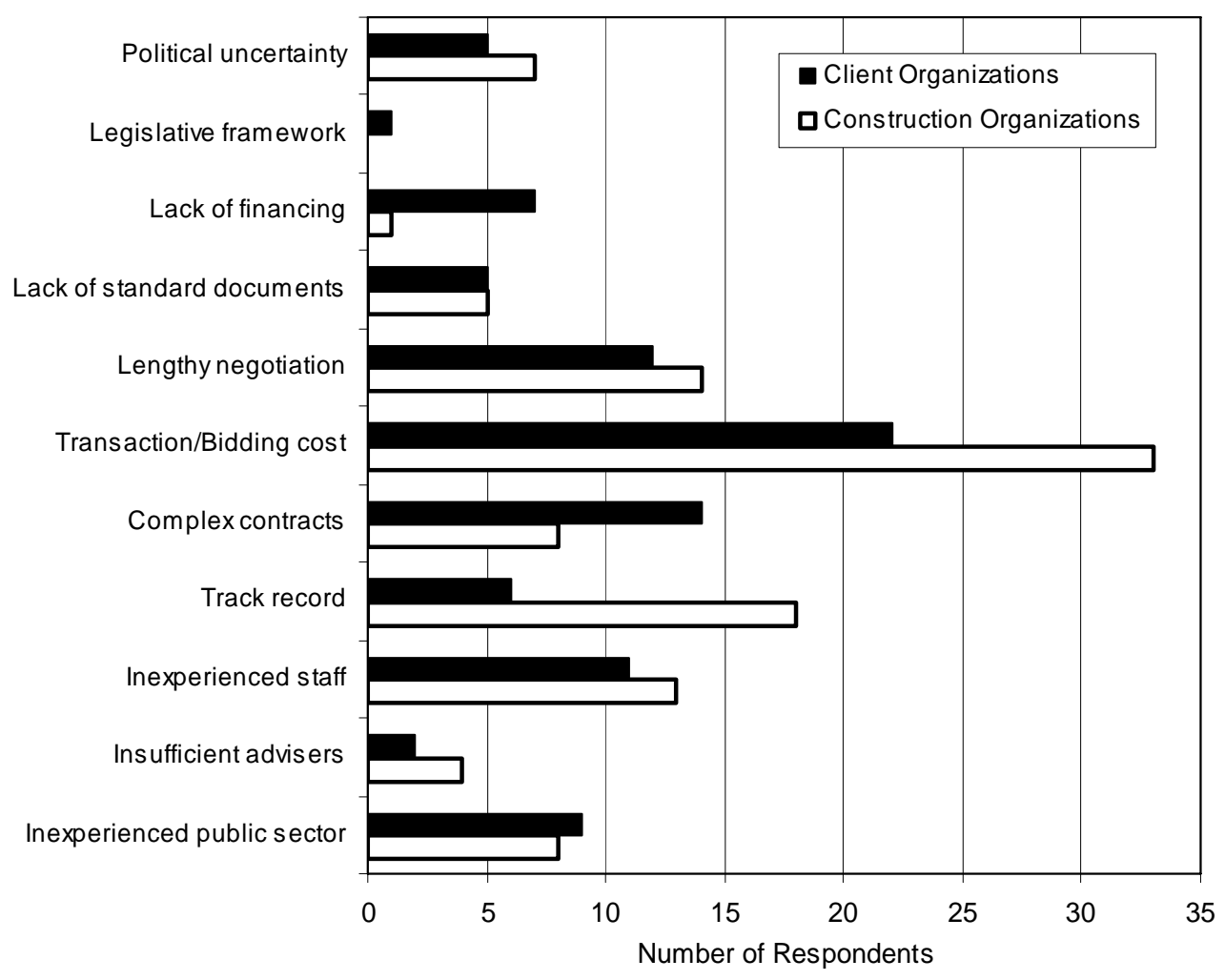

Figure 2: Barriers to Participation in Private Finance Initiative 


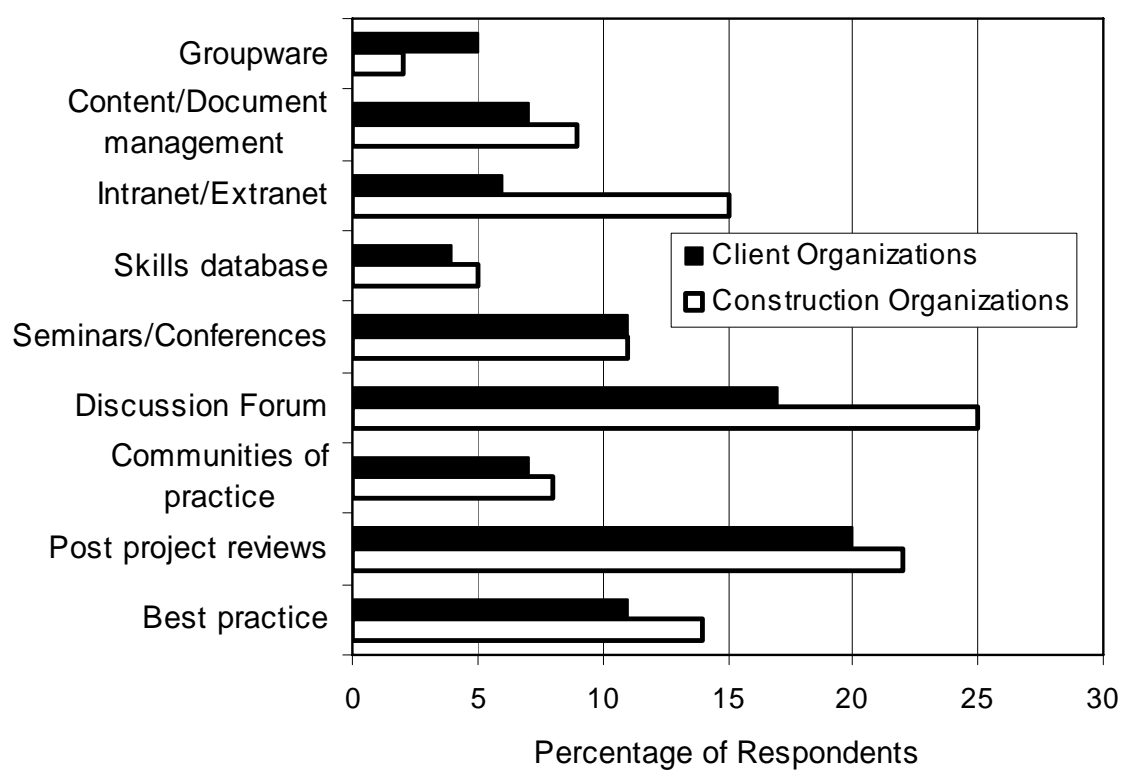

Figure 3: Tools used for capturing Private Finance Initiative knowledge 


\section{List of Figures}

Figure 1: Motivation for Involvement in Private Finance Initiative Projects

Figure 2: Barriers to Participation in Private Finance Initiative

Figure 3: Tools used for capturing Private Finance Initiative knowledge 
List of Tables

Table 1: Organizations Considering Costs High Compared to Traditional Procurement

Table 2: Procurement Periods by Private Finance Initiative sectors (in months)

Table 3: Unique Private Finance Initiative Issues at key stages

Table 4: Organizational Readiness for Sharing Private Finance Initiative Knowledge 